\title{
A model of facilitative communication for support of general hospital nurses nursing mentally ill people
}

Part 2: Model description and evaluation

\author{
TR Mavundla, PhD, Centre for Institutional Excelence and Research, Technikon SA \\ M Poggenpoel, D Phil, Department of Nursing Science, RAU \\ A Gmeiner, PhD, Department of Nursing Science, RAU
}

\section{Abstract}

Part 1 of this article dealt with a full description of the research design and methods. This article aims at describing a model of facilitative communication to support general hospital nurses nursing the mentally-ill. In this article a model of facilitative communication applicable to any general hospital setting is proposed. Fundamental assumptions and relationship statements are highlighted and the structure and process of facilitative communication is described according to the three steps employed: 1) assisting the general hospital nurse learn the skill; 2) assisting the general hospital nurse practise the skill in order to develop confidence; and 3) using the skill in a work setting. The guidelines for operationalising this model are dealt with in the next article. The evaluation of the model is also briefly described.

\section{Introduction}

A model of facilitative communication that offers support to general hospital nurses nursing the mentally-ill is presented. Its structure and process entails three phases which are: 1) assisting the general hospital nurse learn the skill; 2) assisting the general hospital nurse build confidence through practising of the skill; and 3) utilisation of the skill by the general hospital nurse in her daily duties or activities. Phase one of the model details the interaction between the general hospital nurse and the advanced psychiatric nurse. In this phase the advanced psychiatric nurse facilitates the general hospital nurse's acquisition of facilitative communication skills. The advanced psychiatric nurse assists the general hospital nurses in the application of the strategy of reflection in order to learn the skill. This phase acts as a prerequisite for the second phase.

In the second phase of the model the advanced psychiatric nurse helps the general hospital nurse gain confidence in the utilisation of facilitative communication skills acquired in phase one through continuous practice. This is achieved through the utilisation of the process of external feedback which is given to the general hospital nurse by an advanced psychiatric nurse. This is done to improve proficiency in the skills acquired. During this phase, the general hospital nurse is also observed for certain attitudes that are used together with facilitative communication skills. These attitudes are important because they indicate how people are treated by general hospital nurses. This phase forms a prerequisite for phase three.

Phase three of the model entails the utilisation of facilitative communication skills by the general hospital nurse in his/her working environment. By this phase general hospital nurse should have gained confidence in skills utilisation. The process of this phase is facilitated by self-introspection on the part of a general hospital nurse, necessitating the ability to apply internal feedback and questioning skills. Internal feedback and questioning skills assist the general hospital nurse in the use of dialogue, discourse and narratives in his/her interaction with patients, other nurses, doctors, families, and nurse managers. During this phase, the general hospital nurse should be an interpersonal, competent facilitative communicator. Therefore, figure 1 gives the structure of the model.

\section{Assumptions:}

This model is based on a number of assumptions (some of which have been taken from the paradigm guiding this research), communication model, and those that emerge from this model in particular (Mavundla, 1997:114-115).

Assumptions taken from the Nursing for the Whole Person Theory:

1. The individual is a spiritual being who functions in an integrated biopsychosocial manner to achieve his quest for wholeness.

2. The individual interacts with his internal and external environments holistically.

3. The whole person nursing approach to individuals focuses simultaneously on spiritual, mental, and physical aspects of wholeness. 


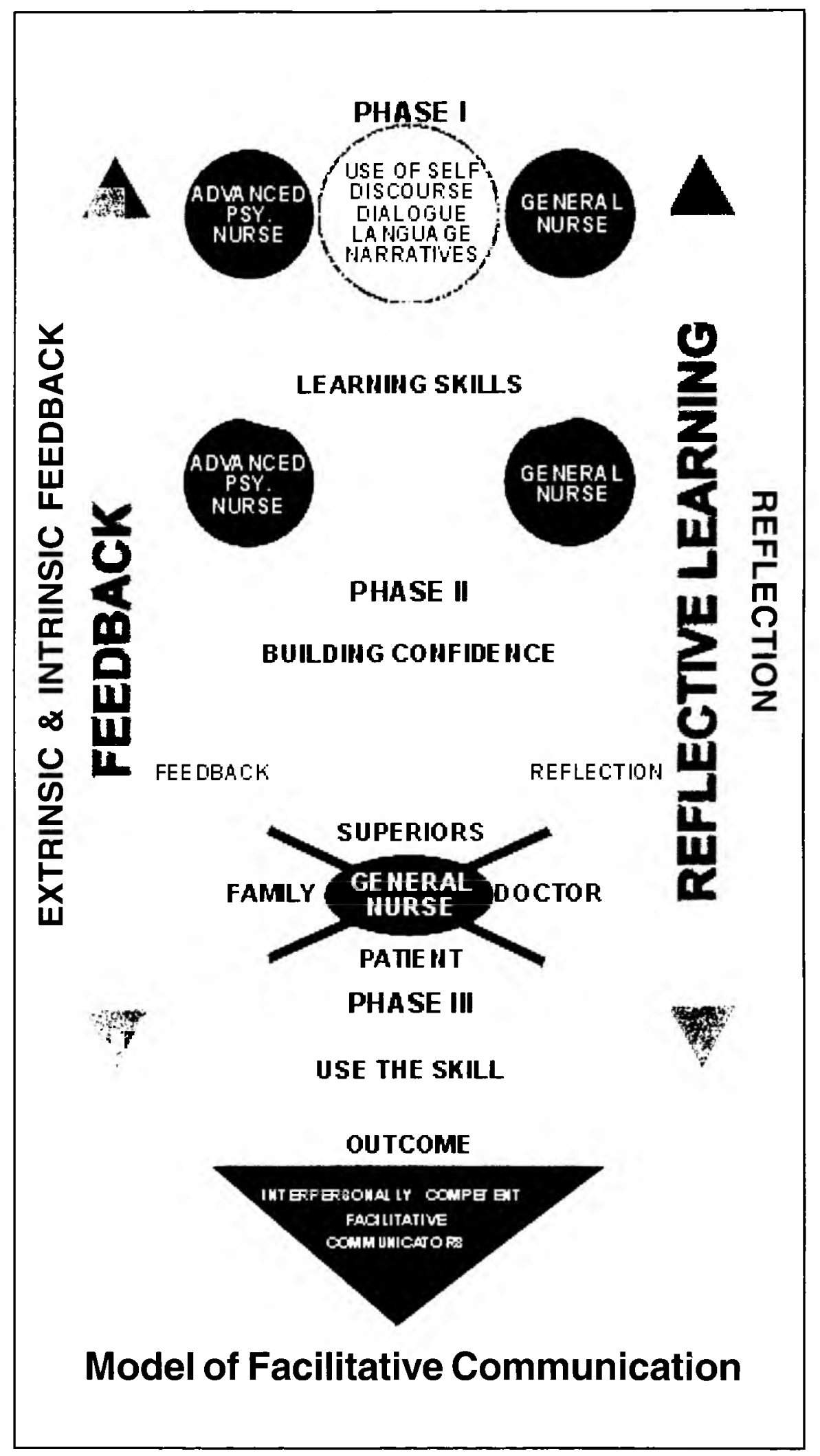

8. An advanced psychiatric nurse, in her capacity as a source of support, guides nurses towards the attainment of effective facilitative communication skills.

9. In order for nurses to develop into facilitative communicators, they should adopt an attitude that encourages openness and curiosity.

10. Reflective learning encourage nurses to view interactions critically during the process of learning facilitative skills.

11. Facilitative communicators use internal feedback in the absence of external feedback. 12. The utilisation of facilitative communication skills by the nurse decreases the rate of patient violence in medical-surgical units.

\section{The Purpose of the Model}

The main purpose of this model is to provide a theoretical basis for the creation of a context for facilitating communication within a general hospital setting. In this model the advanced psychiatric nurse (as a resource) creates a learning context where the general hospital nurse can master the skills of facilitative communication (Mavundla, 1997:115).

The objective of this model is to promote clear, efficient, and appropriate conversations between general hospital nurses and patients, other nurses, doctors, families, and nursing managers. Therefore, the general hospital nurse will develop into an interpersonally competent facilitative communicator (Mavundla, 1997: 115).

\section{Definition of Concepts in the model}

The following concepts together create the model for facilitative communication within a general hospital:

\section{Facilitation of Communication}

It is a process of interaction whereby an advanced psychiatric nurse as a resource, creates a learning context (cognitive domain) in which the general hospital nurse, who is

Assumptions taken from communication:

4. Interpersonally competent facilitative communicators are made and not born.

5. An individual can learn to communicate in competent, caring, and confident ways.

6. An individual can replace ineffective and non-therapeutic communication habits with helpful facilitative communication skills.

7. An individual can add to his/her communications repertoire so that he/she develop confidence in his/her ability to facilitate communication in a variety of situations. viewed as unskilled can master skills of facilitative communication. She uses strategies of reflection and feedback (affective domain) with the aim of helping the general nurse "open up" and use herself more therapeutically. She also helps the general hospital nurse in the use of narratives, dialogue, language and discourse as vehicles for understanding patients' problems. This assists the general hospital nurse to develop into a competent facilitative communicator (psychomotor domain) in his/her interactions with patients, other nurses, families, doctors and nurse managers within a general hospital context (Mavundla, 1997:103). 


\section{The Advanced Psychiatric Nurse}

An advanced psychiatric nurse is a nurse with a clinical master's degree in psychiatric nursing with additional clinical experience under the supervision of an advanced psychiatric nurse and/or field specialist in another related speciality. He / she possesses an in-depth knowledge and skills in advanced psychiatric nursing. In this model the advanced psychiatric nurse is an agent who assists general hospital nurses master facilitative communication skills (Greeff \& Poggenpoel, 1993:24).

\section{The General Hospital Nurse}

A general hospital nurse is a professional nurse employed in a general hospital setting who at one time or another renders nursing care to mentally ill people within her/his unit. He / she should be registered with the South African Nursing Council as a nurse. In this model she is viewed as an unskilled recipient of facilitative communication skills, who then proceeds to use them in her unit viz-a-viz other nurses, nursing managers, doctors, patients and families (Mavundla, 1997:11).

\section{Environment}

This comprises the internal as well as external environment of a nurse. In this model, the external environment refers to the general hospital environment, i.e. patients, other nurses, family, doctors, and nursing managers. Therefore, the following people are found in the external environment of a general hospital nurse and interact with her on a daily basis:

\section{Patient}

A patient in this model refers to any mentally ill person presenting him/herself as afflicted with both a physical and mental illness in a general hospital setting (Mavundla, 1997:11).

\section{Family}

This refers to any person who communicates with a general hospital nurse on behalf of the patient. This person may be related by blood or friendship to the patient who is admitted or in the process of admission.

\section{Other Nurses}

Of concern here are all those nurses who work as subordinates of, or colleagues to, general hospital nurses within the general hospital wards. These nurses may be under supervision or given information regarding the care of the mentally-ill within the ward (Mavundla, 1997:117).

\section{Nursing Managers}

This term refers to anyone who is charged with the responsibility of supervising the practice of general hospital nurses. She is also required to render support to them regarding the care of the mentally-ill (Mavundla, 1997: 118).

\section{Doctors}

A doctor in this model refers to any medical practitioner who work hand in hand with general hospital nurses with regard to the care of the mentally-ill.

\section{Relationship Statements}

The relationship statements applicable to this model are as follows, starting with the central statement:

* Facilitation of communication is a process of interaction wherein an advanced psychiatric nurse, assists the general hospital nurse use self, discourse, dialogue, narratives, and language in order to improve the manner in which she communicates with patients, families, other nurses, doctors and nursing managers within the general hospital context.

Further relationship statements from the model are as follows:

* The role of an advanced psychiatric nurse as a resource encourages the mastering of facilitative communication skills by the general hospital nurse so that she develops from a perspective of an unskilled communicator to that of a competent facilitative communicator.

* The main purpose of facilitative communication is to create contexts for the general hospital nurse to communicate clearly, efficiently, and appropriately with patients, other nurses, doctors, families and nursing managers.

* The nurse can achieve competency as a facilitative communicator by engaging in a continuous dialogue with her innerself by utilising reflective (facilitative) questions and statements.

* The general hospital nurse's ability to respond positively to her internal feedback and that of others about the manner in which she communicates also improves herself as a facilitative communicator.

* The use facilitative communication skills by the general hospital nurse decreases symptoms of mental illness among the mentally-ill thus promoting the mental health of both nurse and patient.

* Facilitative communication skills used by general hospital nurses offer a peaceful ward/unit environment for both nurse and patient.

\section{Process description of the model}

The process of facilitation of communication involves the creation of a context by the advanced psychiatric nurse using facilitative communication wherein the general hospital nurse can master the skills of facilitating communication between herself and patients, other nurses, doctors, families, and nursing managers. In order to facilitate this process of mastering skills, the advanced psychiatric nurse (facilitator) should assist the general hospital nurse's (participant) passage through three interdependent and interrelated phases. These phases are: 1) Assisting the general hospital nurse in the learning of use of the skill; 2) Assisting the general hospital nurse builds confidence in the practice of the skill; and 3) Utilisation of the skill in practice, or meeting the challenges in general hospital contexts with patients, other nurses, doctors, families and nursing managers (Mavundla, 1997:117). 


\section{PHASE 1: Assisting the General Hospital Nurse In Learning the Skill: The Cognitive Domain}

The development of the cognitive domain is based on the view that most of the participants involved in the time of research which produced this model verbalised the fact that they did not possess the knowledge and skills to nurse or communicate effectively with mentally ill people in their care. It is also based on the fact that facilitative communicators are not born, but are rather developed through learning. Therefore, this phase deals with the creation of the context in which the general hospital nurse may master facilitative communication skills.

This phase addresses the "What" question: What are facilitative communication skills? They are broad-based open-ended questions. They are used by general hospital nurses to encourage clients to discuss their problems in a descriptive manner in which various answers may be possible.

\section{Facilitative Communication skills:}

It is important to note that facilitative communication skills consist of statements and questions. The first portion of the section discusses the facilitative statements and later the facilitative questions in the following manner:

Facilitative statements are: reflecting content; reflecting feelings; imparting information; clarifying; paraphrasing; checking perception; questioning; structuring; pinpointing; linking; giving feedback; confronting, summarising and processing (Haber, 1992: 133-144; Kneisl, 1992: 148-152). These facilitative statements are elaborated on in the following sub-headings:

Reflection involves two dimensions of communication: content and feeling.

Reflecting the content of a message implies repeating a client's basic statements. This provides the client with an opportunity to hear and think about what he or she has said. The danger inherent in content reflection is that it can become hollow repetition in parrot fashion. Therefore, content reflection should not be overused since it then loses its therapeutic value.

Reflecting feelings means verbalising what is implied or hinted at by a client. In reflecting feelings, the general hospital nurse seeks to understand the underlying content. Themes, patterns, and indirect expressions of thoughts and feelings emerge as the nurse analyses what the client is really expressing. The general hospital nurse goes beyond what the client has explicitly stated and provides additional material for the client to consider. Verbalising the implied is useful because it helps provide an objective picture of the situation and helps the client view problems in greater depth and with increased accuracy.

Imparting information occurs when you share objective and factual information such as what you know about a particular college in terms of student enrolment, types of programs, and so on. It's important for the general hospital nurse to separate informing from advising, the latter of which is subjective and verges on telling the patient what to do.

Clarifying is an attempt to focus on, or understand, the basic nature of a patient's communication when this is vague, confusing, or unclear. Clarification is usually necessary because patient's communication is not always direct and straightforward. It becomes a real problem when clients are out of touch with reality, intoxicated, or reluctant to share feelings with another person.

Paraphrasing a paraphrase is a verbal statement that is interchangeable with the client's statement although the words may be synonyms of words the clients has used.

Confronting involves providing the client with honest feedback about what is really happening.

Checking Perception means sharing how one person perceives and responds to another.

Questioning is a very direct way of speaking with clients. But when used io excess, questioning controls the nature and range of the client's responses. Questioning can be useful when the nurse is seeking information.

Structuring is an attempt to create order or evolve guidelines. The general hospital nurse helps the client to become aware of problems and the order in which the client might deal with them.

Pinpointing calls attention to certain kinds of statement and relationships.

Liking in linking, the general hospital nurse responds to the client in a way that ties two events/ experiences/ feelings/ or persons. The general hospital nurse can use linking to connect past experience with current behaviours.

Giving Feedback helps others become aware of how their behaviour affects us and how we perceive their actions. Responding with feedback can provide therapeutic self-disclosure.

Processing is a complex and sophisticated technique. Process-related comments direct attention to the interpersonal dynamics of the nurse-client experience. These dynamics are illustrated in the content, feelings, and behaviour expressed.

Summarising by summarising, the general hospital nurse synthesizes what has been communicated during a supportive session and highlights the major affective and cognitive themes. Thus, summary is a type of clarification. This response is important at the end of a session or during the first part of a subsequent session. Summarising is beneficial both to the general hospital nurse and the client who participates and agrees with the summary. It also provides an opportunity for the general hospital nurse to encourage the client to share his or her feelings about the former and the session itself.

Facilitative questions include the following (Kneils, 1992:148152): observe, describe, analyse, formulate, validate, and test. These facilitative questions are also elaborated on in the following sub-headings:

Observe-implies to notice what goes on or what went on. These questions are explorative in nature, they require the patient to give the information needed in detail e.g. "Tell me about yourself?". 
Describe-it implies to be able to recall and tell the details and circumstances of a particular event or experience.

Analyse - to be able to review and work over the data with another person to gain greater understanding

Formulate- to be able to restate in a clear, direct way the relationship between thoughts, feelings, and experience

Validate - to be able to confirm with another person one's thoughts, feelinng, and perceptions

Test- the ability to try out new thoughts, feelings, or behaviors

\section{The Process of Learning the skill:}

The reflective thinking process is used as a method of learning the skill. Reflection involves both inward and outward activities. The inward activities are concerned with due attention to feelings and thoughts whereas the external focus is on behaviours and situations. It uses asking reflexive questions, hypothesizing, reality testing, and evaluating as skills. The methods of introspection, writing, and discussion may be used (Betts, 1995: 62-63). In this phase, one turns the experience into a system of learning. The advanced psychiatric nurse encourages the general hospital nurse to reflect on patients' problems through the use of the following medium or vehicle of communication:

A dialogue implies a conversation or a talk between two people. These people may have similar or differing opinions about certain issues (Barrow, 1989:142; Diekelmann, 1990:302; Perry \& Moss, 1988:37; Benner (1984:24). In this model a dialogue may be between the general hospital nurse and the patient. other nurses, family, doctors, and nursing managers.

A narrative or Story implies a report of an event, it may only be one sentence long, but it is ussually longer (Parry, 1991:37; Ventres, 1994:139). In this model this may entail stories of patients, other nurses, families, doctors, and nursing managers.

Discourse implies a meaning of certain communication in its context. It may be lengthy and address a serious issue or topic. It may be done in a form of a speech or lecture (Hornby, 1992:342; Flowerdew, 1996: 560-565; Handwerker, 1996: 101).

Language is the system of sounds, words, patterns used by humans to communicate thoughts and feelings (Bell, Wright \& Watson, 1992: 35-38). The language may be used between the advanced psychiatric nurse and the general hospital nurse or the general hospital nurse and patients, other nurses, families, doctors, and nursing managers.

In this phase the advanced psychiatric nurse (agent) takes the role of facilitator and the general hospital nurse (receiver) assume the role of participant. Figure 2 gives the roles assumed by both the advanced psychiatric nurse and the general nurse in the process of learning the skill. Therefore, this phase forms the prerequisite for phase 2 .

[Facilitator] $>$ [Participant]

Figure 2: Roles During Learning of the Skill

\section{PHASE 2: Assisting the General Hospital Nurse towards Building Confidence: The Affective Domain}

The second phase of this model entails assisting the general hospital nurse gain confidence in the skills mastered in the first phase. This phase is based on the assumption that one needs to continuously practise the skill to ensure confidence. Since general hospital nurses verbalised a lack of skills among themselves, there is a need for learned skills to be practised. This phase addresses the "how to" questions of the skill which means that in this phase we are interested in the manner in which the general hospital nurse communicates. This phase entails guiding the general hospital nurse in the practice of the skill using the process of giving feedback in order to achieve proficiency.

This phase helps the general hospital nurse master the appropriate ingredients to assist her develop certain attitudes and certain values of facilitative communication (Kneisl, 1992: 148152). At this level the general hospital nurse should develop the following attitudes when communicating with patients, other nurses, doctors, families and the nursing managers:
1. empathy
2. respect
3. genuiness
4. immediacy
5. warmth

The above-mentioned facilitative communication attitudes are further explained in the following sub-heading (Kneisl, 1992: 148-152):

Responding with Empathy: most theorists believe that empathy is the most important dimension in the helping process. Without a high level of empathic understanding, general hospital nurses have no real basis for helping. Empathy facilitates interpersonal exploration.

Responding with Respect demonstrates that the general hospital nurse values the integrity of the client and has faith in the client's ability to solve problems, given appropriate help. By encouraging clients to put forward possible plans of action, the nurse conveys respect for their ability to take charge of their own destiny. Giving advice, by contrast, conveys a directly opposite message.

Responding with Genuineness: genuineness refers to the ability to be real or honest with others. To be effective, genuineness must be timed properly and based on a solid relationship. Clients who can experience the authenticity of the nurse can risk greater genuineness and authenicity themselves. The general hospital nurse who is genuine is more likely to deal with, and eventually help, the client resolve real problems rather than just those that are "safe" or socially acceptable.

Responding with Immediacy means responding to what is happening between the client and the nurse in the here-and-now. Because this dimension may involve the feelings of the client toward the nurse, it can be one of the most difficult to achieve.

Responding with Warmth: warmth is so closely linked with empathy and respect that it is seldom communicated as an independent dimension. It is important, however, to note some 
additional points about the expression of warmth. Effusive, chatty, "buddy-buddy" behaviour should not be confused with warmth. Warmth is most often conveyed in communications of respect and empathy.

The general hospital nurse should be aware of, and accept of the client's right to maintain distance; warmth and intimacy cannot be forced. Initially, high levels of warmth can be counterproductive for clients who have received little warmth from others in their lives, or who have been taken advantage of by others. Warmth alone is insufficient for building a relationship and solving problems. This indicates that she (the nurse) should be able to respond with respect or immediacy.

As indicated at the beginning of this phase, feedback is used as a process of this phase and should be given to general hospital nurses so as to improve their interaction with other people. As indicated earlier, The nurse may use both intrinsic and extrinsic feedback (Dickson, Hargie \& Marrow, 1989:23). She uses intrinsic feedback during an interaction with people so as to responds accordingly. Intrinsic feedback is available as a natural consequence of performing a skill. The notion will be recalled of behaviour being responded to by the other involved in the encounter thus providing feedback which can be acted upon in order to achieve a certain goal. Therefore, this feedback is intrinsic to the skill. On the other hand, the nurse receives extrinsic feedback directly relating to interaction with advanced psychiatric nurses and/or others. Extrinsic feedback refers to supplementary information, which, while not forming an integral part of the skill, enables decisions to be reached about its accomplishment. It can be supplied by the advanced psychiatric nurse in the form of comments. Once the general hospital nurse has attained confidence in practising the skill together with specific attitudes associated with it, she can put it into practice in her daily working activities. The following phase deals with the application of the learned skills in practice.

\section{PHASE 3: Utilising Communication Skills In Work Context: The Psychomotor Domain}

This phase involves putting into practice what has been learnt. In this phase the general hospital nurse uses facilitative communication in order to understand and communicate effectively within her working environment. This phase addresses the "where" and "whom" questions.

The general hospital nurse facilitates communication in her working environment which is the context in which this activity takes place. Communication is with patients, nurses, doctors, nursing managers and families.

\section{Process of facilitating Communication:}

The process of facilitating communication involves the application of reflective thinking processes and intrinsic feedback. The general hospital nurses engages in a dialogue with herself, in which she debates the situations and behaviours of others with whom she is dealing. On the other hand, she uses intrinsic feedback to understand the cues and responses of the people she communicates with towards understand in the process of communication, and to choose appropriate responses
The combination of the above-mentioned two processes help the nurse to "open up" and become increasingly involved in appropriate dealing with others for use of both internal feedback and reflection during the process of implementing the skill).

Owing to the application of above-mentioned, the general hospital nurses will be able to facilitate communication in the following manner:-

1. Initiating and maintaining communication to patients

2. Informing relatives about the patient's condition

3. Imparting information about the care of the patient to other nurses

4. Dealing with doctors about patients behaviours, and

5. Informing their managers about unit problems

\section{Evaluation of the model}

It has been indicated earlier that the model of facilitative communication will be given to experts for evaluation. The model was found to be appropriate for the setting it was intended for and its concepts were mature.

\section{Conclusion}

This article dealt with a comprehensive description of the structure and process of the model of facilitative communication in support of general hospital nurses assigned the task of nursing the mentally-ill. Guidelines for operationalising the model as regards the education of nurses were furnished. Both the model and guidelines for its operationalisation were constructed. It is important to implement these guidelines in order to ensure adequate patient care. This will promote the mental health of the mentally-ill, their families who come to visit them, doctors, nursing managers and other nurses within general hospital settings.

\section{References}

BARROW, N 1989: Nursing-a new tomorrow. International Nursing Review. 36, 141-144.

BELL, JM; WRIGHT, LM \& WATSON, WL 1992: The medical map is not the territory; or "Medical family therapy"? Watch your language! Family Systems Medicine. 10 (1), 35-38.

BENNER, P 1984: From novice to expert: Excellence and power in Clinical nursing. Addison-Wesley, Menlo Park, Carlifornia.

BETTS, A 1995: Improving Communication. Eds: Ellis, RB; Gates, RJ \& Kenworthy: Interpersonal Communication in Nursing: Theory and Practice. Churchhill Livingstone: Edinburgh.

DICKSON, DA; HARGIE, O \& MARROW, NC 1989: Communication skills Training for health professionals: An instructor's hand book. Chapman and Hall: London.

DIEKELMANN, N 1990:. Nursing Education. Caring, dialogue, and practice. Journal of Nursing Education. 29, 300-305.

FLOWERDEW, J 1996; Discourse and social change in contemporary Hong Kong. Language in society. 25 (4), 557-586. 
GREEFF, M \& POGGENPOEL, M 1993: A model for psychiatric nursing accompaniment of a patient with a mental discomfort. Part 1: Research Methods and Design. Curationis. 16(1): 23-32.

HABER, J 1992: Therapeutic Communication. Ed. Haber, J; McHanon, Al; Price-Hoskins, P \& Sideleau, BF: Psychiatric Nursing, Fourth Edition. St Louis: Mosby Year Book.

HANDWERKER, WP 1996: Power and gender: Violence and affection experienced by children in Barbados, West Indies. Medical Anthropology. 17 (2), 101-128.

HORNBY, AS 1992: Oxford advanced learner's dictionary of current English. Fourth Edition, Oxford University Press, New York.

KNEILS, CR 1992: Communication. Ed. Wilson, HS \& Kneils, CR: Psychiatric Nursing. Redwood City: Addison-Wesley.

MAVUNDLA, TR 1997. A model of facilitative communication for support of general hospital nurses nursing mentally ill people. Unpublished Doctoral Thesis. Auckland Park: Rand Afrikaans University.

PARRY, A 1991: A universe of stories. Familv Process. 30, $37-$ 54.

PERRY, J \& MOSS, C 1988: Generating alternative in nursing: turning curriculum into a living process. The Australian Journal of Advanced Nursing. 35-40.

VENTRES, WB 1994: Hearing the patient's story: Exploring physician-patient communication using narrative case reports. Family Practice Research Journal. 14(2), 139-147. 